\title{
Role of common mental and physical disorders in partial disability around the world
}

Ronny Bruffaerts, Gemma Vilagut, Koen Demyttenaere, Jordi Alonso, Ali AlHamzawi, Laura Helena Andrade, Corina Benjet, Evelyn Bromet, Brendan Bunting, Giovanni de Girolamo, Silvia Florescu, Oye Gureje, Josep Maria Haro, Yanling He, Hristo Hinkov, Chiyi Hu, Elie G. Karam, Jean-Pierre Lepine, Daphna Levinson, Herbert Matschinger, Yoshibumi Nakane, Johan Ormel, Jose Posada-Villa, Kate M. Scott, Matthew Varghese, David R. Williams, Miguel Xavier and Ronald C. Kessler

\section{Background}

Mental and physical disorders are associated with total disability, but their effects on days with partial disability (i.e. the ability to perform some, but not full-role, functioning in daily life) are not well understood.

\section{Aims}

To estimate individual (i.e. the consequences for an individual with a disorder) and societal effects (i.e. the avoidable partial disability in the society due to disorders) of mental and physical disorders on days with partial disability around the world.

\section{Method}

Respondents from 26 nationally representative samples $(n=61259$, age 18+) were interviewed regarding mental and physical disorders, and day-to-day functioning. The Composite International Diagnostic Interview, version 3.0 (CIDI 3.0) was used to assess mental disorders; partial disability (expressed in full day equivalents) was assessed with the World Health Organization Disability Assessment Schedule in the CIDI 3.0.

\section{Results}

Respondents with disorders reported about 1.58 additional disability days per month compared with respondents without disorders. At the individual level, mental disorders (especially post-traumatic stress disorder, depression and bipolar disorder) yielded a higher number of days with disability than physical disorders. At the societal level, the population attributable risk proportion due to physical and mental disorders was $49 \%$ and $15 \%$ respectively.

\section{Conclusions}

Mental and physical disorders have a considerable impact on partial disability, at both the individual and at the societal level. Physical disorders yielded higher effects on partial disability than mental disorders.

\section{Declaration of interest}

R.C.K. has been a consultant for GlaxoSmithKline, Kaiser Permanente, Pfizer, Sanofi-Aventis, Shire Pharmaceuticals and Wyeth-Ayerst; has served on advisory boards for Eli Lilly \& Company and Wyeth-Ayerst; and has had research support for his epidemiological studies from Bristol-Myers Squibb, Eli Lilly \& Company, GlaxoSmithKline, Johnson \& Johnson Pharmaceuticals, Ortho-McNeil Pharmaceuticals, Pfizer and Sanofi-Aventis.
In an era when healthcare expenditure continue to rise progressively worldwide, it is becoming increasingly important to make decisions about the allocation of healthcare resources based on information about the comparative burdens of different disorders. Burden can be defined in terms of condition-specific rates or morbidity and mortality, ${ }^{1}$ but research is increasingly moving beyond these actuarial data to consider additional information about the impairments caused by different disorders, such as the comparative effects of conditions on days out of role $\mathrm{e}^{2,3}$ or role performance. ${ }^{4-8}$ A weakness of previous research is that most studies estimated the extent to which disorders are associated with being totally out of role (i.e. the number of days a person is not at all able to perform as usual). ${ }^{9}$ But there is growing evidence that disorders are also associated with partial disability (i.e. the number of days a person is partially unable to perform as usual).$^{10}$ Moreover, partial disability now may predict full disability later. ${ }^{11}$ These suggestions make the study of partial disability particularly interesting. Investigating partial disability enables us to study the potential broader influence that disorders may have on functional impairment, over and above full disability. There are three important limitations in previous research. First, there are no cross-national analyses on the comparative impact of mental and physical disorders on partial disability. Second, most studies estimated the impact of disorders in the workplace (e.g. Dewa \& Lin, ${ }^{4}$ Dewa et $a l^{5,12}$ ), but studies that go beyond work productivity are much scarcer. Third, most previous research estimated individual effects of mental/physical health on role disability, i.e. the effects of disorders on the daily lives of those who have a disorder, but a public-health societal approach has never been used before.

The current study builds on earlier World Mental Health studies reporting on the impact of mental and physical disorders on total role impairment. ${ }^{13}$ The specific aims of the study were to investigate: (a) the total number of partial disability days per month of respondents with mental and physical disorders; (b) the number of additional partial disability days per month due to mental and physical disorders among those with a disorder ('individual-level effects'); (c) the attributable proportion of mental and physical disorders in the number of partial disability days in the society ('societal-level effects') using population-attributable risk proportions; (d) differences in individual and societal effects of disorders in specific subdomains of partial disability; and (e) the extent to which there are differences in the effects of disorders on partial disability across different income categories.

\section{Method}

\section{Sample}

The World Mental Health (WMH) Surveys were carried out in 26 samples worldwide: Africa (Nigeria, South Africa); the Americas 
(Brazil, Colombia, Mexico, USA), Asia and the Pacific (Japan, New Zealand, in the People's Republic of China: Beijing, Shanghai and Shenzhen), Europe (Belgium, Bulgaria, France, Germany, Italy, The Netherlands, Northern Ireland, Portugal, Romania, Spain, Ukraine); and the Middle East (India, Israel, Lebanon, Iraq). Respondents were selected in most WMH countries using a stratified multistage clustered-area probability sampling strategy. The total sample size was 121902 , with individual country sample sizes ranging from 2357 in Romania to 12790 in New Zealand. The weighted average response rate across all countries was $72.0 \%$. Using World Bank criteria, ${ }^{14}$ countries were classified as low-income (China, Colombia, India, Iraq, Nigeria and Ukraine), middle-income (Brazil, Bulgaria, Lebanon, Mexico, Romania and South Africa) and high-income countries (Belgium, France, Germany, Israel, Italy, Japan, The Netherlands, New Zealand, Northern Ireland, Spain, Portugal and USA). More information on the sample characteristics is reported elsewhere. ${ }^{15}$

\section{Procedures}

Surveys were conducted face to face by trained lay interviewers. Informed consent was obtained before beginning interviews. During interviews, all respondents provided sociodemographic and core diagnostic information. Internal subsampling was used to reduce respondent burden and average interview time and cost by dividing the interview into two parts. Part 1 included the core diagnostic assessment of mental disorders. Part 2 included additional information relevant to a wide range of survey aims, including the assessment of physical disorders. All respondents completed Part 1. All Part 1 respondents who met criteria for any lifetime mental disorder and a probability sample of other respondents were administered Part 2. Part 2 respondents were weighted by the inverse of their probability of selection for Part 2 of the interview to adjust for differential sampling. Analyses in this study were based on the weighted Part 2 subsample, excluding those individuals with full disability $(n=61259)$. Additional weights were used to adjust for differential probabilities of selection within households, to match the samples to population sociodemographic distributions and to adjust for non-response in some of the countries. Standardised interviewer training procedures, World Health Organization (WHO) translation protocols for all study material and quality control procedures for interviewer and data accuracy were consistently applied across all WMH countries in an effort to ensure cross-national comparability. Procedures for obtaining informed consent and protecting participants were approved and monitored for compliance by the institutional review boards of the organisations coordinating the surveys in each country. Sampling and other study characteristics are described elsewhere. ${ }^{15-17}$

\section{Partial disability}

Partial disability days were assessed with a modified version of the WHO Disability Assessment Schedule II (WHODAS-II). ${ }^{18}$ The time frame of the WHODAS-II is the 30 days prior to the assessment. The interpretation of partial disability days goes beyond job productivity and focuses instead on the number of days with functional limitations in daily activities without being fully out of role. Partial disability was expressed in full day equivalents to allow for the variation in the number of disability hours per day. A partial disability day was defined as a day in which respondents (a) had to cut down on what they did, assessed by the following item 'How many days out of the past 30 were you able to work and carry out your normal activities, but had to cut down on what you did or not get as much done as usual because of problems with either your physical health, your mental health, or your use of alcohol or drugs?; (b) had to cut back on the quality of what they did, assessed by the following item: 'How many days out of the past 30 did you cut back on the quality of your work or how carefully you worked because of problems with either your physical health, your mental health, or your use of alcohol or drugs?'; and (c) experienced extreme effort to perform as usual, assessed by the following item: 'How many days out of the past 30 did it take an extreme effort to perform up to your usual level at work or at your other normal daily activities because of problems with either your physical health, your mental health, or your use of alcohol or drugs?. These three items were then added together in order to calculate an aggregate measure of partial disability: ${ }^{18,19}$ number of days people had to cut down on what they did (0.5); number of days people had to cut back on quality of what they did (0.5); and number of days they had extreme effort to perform as usual (0.25). If this sum exceeded 30 , it was recoded to equal 30 giving the sum a range from 0 to 30. These four measures (i.e. cut down on quantity, cut back on quality, took extreme effort and our aggregate measure of partial disability) were considered as the four dependent variables.

\section{Physical disorders}

Physical disorders were assessed with a standard chronic disorders checklist adapted from the US Health Interview Survey. ${ }^{20}$ Such checklists have been shown to yield more complete and accurate reports than estimates derived from responses to open-ended questions. ${ }^{21,22}$ Methodological studies showed moderate to good concordance between such reports and medical records. ${ }^{23,24}$ Ten physical disorders were included in the current report: arthritis, cancer, cardiovascular disease (heart attack, heart disease, hypertension and stroke), chronic back or neck pain, diabetes, frequent or severe headache or migraine, insomnia, neurological (multiple sclerosis, Parkinson's disease and epilepsy or seizures), digestive disease (stomach or intestine ulcer or irritable bowel disorder) and respiratory disease (seasonal allergies such as hay fever, asthma or chronic obstructive pulmonary disease or emphysema). Following standardised procedures for arthritis, back/neck pain, headache, heart attack or stroke, respondents were asked to report whether they had experienced these disorders. For the remaining disorders, the question was prefaced by the phrase 'Have you ever been told by a doctor or health professional that you had any of these conditions?'. The time frame varied across countries and physical disorders: the Western European countries assessed both lifetime and 12-month presence of each disorder. In the rest of the sample that used the computer-assisted version of the questionnaire, some of the chronic disorders were only evaluated for lifetime presence, but for problems that could have remitted, participants were asked whether they still had the disorders in the past 12 months. Finally, those countries using a paper-assisted questionnaire used a 12-month time frame for most symptom-based disorders and lifetime frame for the silent disorders (i.e. individuals not displaying symptoms). The 12-month time frame has been used whenever possible, but for some of the disorders inconsistent time frames were used across countries.

\section{Mental disorders}

Mental disorders were assessed with Version 3.0 of the WHO Composite International Diagnostic Interview (CIDI), a fully structured lay-administered interview designed to generate research diagnoses of commonly occurring DSM-IV mental disorders. ${ }^{25}$ The nine mental disorders considered here include 
mood disorders (major depressive disorder and bipolar I and bipolar II disorder), anxiety disorders (panic disorder and/or agoraphobia, specific phobia, social phobia, generalised anxiety disorder, post-traumatic stress disorder (PTSD)) and substance disorders (alcohol abuse with and without dependence and drug abuse with and without dependence). Only disorders present in the 12 months before interview were considered. Methodological evidence collected in the WHO CIDI 3.0 field trials and later clinical calibration studies showed that all disorders considered here were assessed with acceptable reliability and validity compared with the original $\mathrm{CIDI}^{26}$ as compared with masked re-interviews. ${ }^{27}$

\section{Statistical analysis}

We ran multiple regression models to examine the associations of the independent variables (i.e. the physical and mental disorders) with each of the four dependent variables, controlling for age, gender, employment status and country. As the sample size was too small to allow each of the 524288 (i.e. $2^{19}$ ) logically possible combinations of comorbid disorders to be a separate predictor, several regression models were tested (data available from the author on request). Based on the Bayesian Information Criterion (BIC), the model that provided the best fit for each of the four dependent variables (i.e. the model that included 19 predictors for type and dummy predictors for number of disorders) was the one that was finally chosen. We calculated both individual and societal effects of disorders on partial disability. Individual-level effects refer to the difference in partial disability for those with and without mental or physical disorders, i.e. the additional number of days with partial disability for a respondent with a specific mental/physical disorder. Using simulation, we first estimated the number of days with partial disability from the final selected model. Then we calculated this outcome again but based on the assumption that none of the individuals in the sample had the disorder or condition being evaluated. Differences between these two estimates were averaged across all respondents with the disorder to obtain the individual-level effect of the condition. Society-level effects were estimated using population attributable risk proportions (PARPs). From a public health perspective, such an approach could enable us to identify which disorders will have the most impact when it comes to making decisions about the (re)allocation of scarce resources in the general population. The PARP is to be interpreted as the proportion of partial disability days in the general population that may be reduced when a specific disorder is removed. First, estimates of each of the four disability measures were calculated based on the actual data and then, second, under the counterfactual assumption that the disorder in question had been removed from the population. We used the two estimates of predicted days with partial disability, and then averaged both estimates across the entire population and computed the percentage difference between them. The same procedures were used to calculate total effects of any physical disorder, any mental disorder and any disorder.

Standard errors for prevalence rates were estimated using the Taylor series linearisation method ${ }^{28}$ implemented in the SUDAAN software package (Software for Survey Data Analysis, version 8.1 on UNIX-Solario/SUN OS) to account for the complex sample design. Standard errors of individual and societal-level effects were estimated using SAS macros for Jackknife Repeated Replications method (JRR) for complex sample data. The macros written for this purpose were used to obtain standard errors of the simulated estimates of individual-level and societal-level disorder effects. Significance tests were consistently evaluated using 0.05-level, two-sided, design-based tests.

\section{Results}

Our sample consisted of 61259 respondents from 26 surveys: 15702 from lower-income, 14473 from middle-income and 31084 from higher-income countries. Respondents were on average 42 years old. Almost 52\% were female and just above a third (36.5\%) were not married. The proportion of respondents with completed high-school education varied between $44.8 \%$ in middle- and up to $69.5 \%$ in higher-income countries. Overall, $41.3 \%$ of the sample was not working. More details on the sample characteristics can be found elsewhere. ${ }^{15}$

\section{The distribution of days with partial disability}

The mean number of days with partial disability was 1.6 a month (Table 1). About one in five (i.e. 21.6\%) reported at least 1 day with partial disability in the previous month. Among these, the average number of days with partial disability days approximated 7.3 per month.

\section{Prevalence of physical and mental disorders}

More than half $(57.2 \%)$ of the respondents had one or more disorders. The proportion of respondents with a physical condition $(52.6 \%)$ is considerably higher than the proportion with a mental disorder (14.9\%). Back/neck pain, cardiovascular disease and respiratory disease were the most common physical disorders (all estimates in the 17-22\% range). Major depression episode, specific phobia and social phobia were the most common mental disorders (all in the $2-5 \%$ range) (online Table DS1). Prevalence estimates of physical disorders increased with income level: $44.9 \%$ in low-, $51.7 \%$ in middle- and $56.9 \%$ in high-income countries. Comparable figures were obtained for the prevalence of mental disorders: $11.8 \%$ in low-, $15.1 \%$ in middle- and $16.4 \%$ in high-income countries (online Table DS2).

\section{Partial disability among respondents with physical and mental disorders}

The average number of partial disability days varied considerably by type of disorder, but were in the 2.38-4.57 range for people with physical disorders (median 3.31 days) and in the 2.40-5.84 range for mental disorders (median 4.37 days). Post-traumatic stress disorder (5.84 days), generalised anxiety disorder (4.96 days) and bipolar disorder (4.60 days) were the disorders with the highest number of partial disability days. Overall, respondents with mental disorders systematically reported $15-28 \%$ more partial disability days than respondents with physical disorders. When partial disability days were broken down into the three subdomains, the impact of disorders appeared to be comparable (online Table DS1).

\section{Individual-level effects of physical and mental disorders on partial disability days}

Table 2 shows the additional days per month with partial disability in respondents with a physical/mental disorder compared with those without. The presence of a disorder was associated with an additional 1.58 disability days/month (or 19 days/year). Specifically, PTSD (1.92 additional days/month), depression (1.65 additional days/month) and bipolar disorder (1.70 additional days/month) were among the disorders with the highest additional partial disability. Mental and physical disorders yielded comparable disability, a finding that was slightly more pronounced in high-income countries. Indeed, the estimated impact of disorders was higher in high-income (1.91 additional 


\begin{tabular}{|c|c|c|c|c|}
\hline & $\begin{array}{l}\text { Low-income } \\
\text { countries }\end{array}$ & $\begin{array}{l}\text { Middle-income } \\
\text { countries }\end{array}$ & $\begin{array}{l}\text { High-income } \\
\text { countries }\end{array}$ & $\begin{array}{c}\text { Total } \\
\text { sample }\end{array}$ \\
\hline \multicolumn{5}{|l|}{ Had to cut down quantity } \\
\hline Any days had to cut down quantity, \% (s.e.) & $16.2(0.4)$ & $13.0(0.4)$ & $19.0(0.3)$ & $16.8(0.2)$ \\
\hline 1 day & $12.9(0.9)$ & $10.5(0.9)$ & $12.8(0.5)$ & $12.4(0.4)$ \\
\hline 2 days & $22.3(1.2)$ & $16.0(1.1)$ & $16.8(0.6)$ & $18.0(0.5)$ \\
\hline $3-5$ days & $27.5(1.1)$ & $24.2(1.1)$ & $25.5(0.7)$ & $25.8(0.5)$ \\
\hline $6-10$ days & $18.8(1.2)$ & $15.2(1.0)$ & $14.7(0.6)$ & $15.8(0.5)$ \\
\hline $11-20$ days & $10.1(0.8)$ & $11.9(0.9)$ & $12.2(0.5)$ & $11.7(0.4)$ \\
\hline 21-30 days & $8.5(0.8)$ & $22.1(1.2)$ & $17.9(0.7)$ & $16.4(0.5)$ \\
\hline Number of cut down days, mean (s.e.) & $1.2(0.05)$ & $1.4(0.06)$ & $1.9(0.05)$ & $1.6(0.03)$ \\
\hline Number of cut down days, among those with any cut down days: mean (s.e.) & $7.3(0.2)$ & $11.1(0.3)$ & $9.9(0.2)$ & $9.5(0.1)$ \\
\hline \multicolumn{5}{|l|}{ Had to cut back quality } \\
\hline Any days had to cut back quality, \% (s.e.) & $13.1(0.4)$ & $9.2(0.3)$ & $14.7(0.3)$ & $13.0(0.2)$ \\
\hline 1 day & $12.4(1.1)$ & $11.7(1.0)$ & $12.3(0.6)$ & $12.3(0.5)$ \\
\hline 2 days & $21.3(1.4)$ & $16.8(1.2)$ & $18.5(0.7)$ & $18.9(0.6)$ \\
\hline $3-5$ days & $31.2(1.4)$ & $31.4(1.5)$ & $29.9(0.8)$ & $30.5(0.6)$ \\
\hline $6-10$ days & $19.3(1.3)$ & $17.0(1.4)$ & $14.9(0.6)$ & $16.4(0.5)$ \\
\hline $11-20$ days & $10.0(0.9)$ & $12.5(1.0)$ & $11.6(0.6)$ & $11.3(0.5)$ \\
\hline 21-30 days & $5.7(0.7)$ & $10.7(0.9)$ & $12.7(0.6)$ & $10.6(0.4)$ \\
\hline Number of cut back days, mean (s.e.) & $0.9(0.03)$ & $0.8(0.04)$ & $1.2(0.03)$ & $1.0(0.02)$ \\
\hline Number of cut back days, among those with any cut back days: mean (s.e.) & $6.7(0.2)$ & $8.3(0.3)$ & $8.5(0.2)$ & $8.0(0.1)$ \\
\hline \multicolumn{5}{|l|}{ Took extreme effort } \\
\hline Any days took extreme effort, \% (s.e.) & $11.8(0.3)$ & $9.4(0.3)$ & $16.3(0.3)$ & $13.5(0.2)$ \\
\hline 1 day & $11.2(1.1)$ & $11.8(1.4)$ & $12.4(0.6)$ & $12.1(0.5)$ \\
\hline 2 days & $17.2(1.2)$ & $15.9(1.2)$ & $17.5(0.6)$ & $17.1(0.5)$ \\
\hline $3-5$ days & $31.3(1.5)$ & $29.7(1.6)$ & $27.2(0.7)$ & $28.5(0.6)$ \\
\hline 6-10 days & $21.5(1.3)$ & $18.2(1.4)$ & $16.6(0.7)$ & $17.9(0.5)$ \\
\hline $11-20$ days & $10.0(0.8)$ & $11.2(0.9)$ & $11.3(0.6)$ & $11.0(0.4)$ \\
\hline 21-30 days & $8.8(0.9)$ & $13.2(1.0)$ & $15.1(0.6)$ & $13.4(0.5)$ \\
\hline Number of extreme effort days, mean (s.e.) & $0.9(0.04)$ & $0.8(0.04)$ & $1.5(0.04)$ & $1.2(0.02)$ \\
\hline Number of extreme effort days, among those with any extreme effort days: mean (s.e.) & $7.7(0.3)$ & $8.8(0.3)$ & $9.1(0.2)$ & $8.7(0.1)$ \\
\hline \multicolumn{5}{|l|}{ Partial disability } \\
\hline Any days with partial disability, \% (s.e.) & $19.7(0.4)$ & $15.4(0.5)$ & $25.4(0.4)$ & $21.6(0.2)$ \\
\hline 1 day & $20.3(1.0)$ & $15.6(0.9)$ & $19.2(0.5)$ & $18.9(0.4)$ \\
\hline 2 days & $15.7(0.9)$ & $14.5(0.9)$ & $16.0(0.6)$ & $15.7(0.4)$ \\
\hline $3-5$ days & $26.5(1.2)$ & $21.8(1.1)$ & $23.7(0.5)$ & $24.0(0.5)$ \\
\hline $6-10$ days & $16.9(0.9)$ & $15.1(0.8)$ & $14.4(0.5)$ & $15.1(0.4)$ \\
\hline $11-20$ days & $15.2(0.7)$ & $23.9(1.1)$ & $16.8(0.5)$ & $17.6(0.4)$ \\
\hline 21-30 days & $5.4(0.6)$ & $9.2(0.7)$ & $9.9(0.4)$ & $8.7(0.3)$ \\
\hline Number of days with partial disabilities, mean (s.e.) & $1.2(0.04)$ & $1.3(0.05)$ & $1.9(0.04)$ & $1.6(0.03)$ \\
\hline Number of days with partial disability among those with any partial disability, mean (s.e.) & $6.2(0.2)$ & $8.2(0.2)$ & $7.4(0.1)$ & $7.3(0.1)$ \\
\hline
\end{tabular}

days/month) than middle-income (1.14 additional days/month) or lower-income countries (1.15 additional days/month; online Table DS3).

The multivariate interactive regression model revealed that all 19 disorders were significantly associated with additional partial disability days, even when data were broken down for the three subdomains (online Table DS4). Depression and bipolar disorder were most predictive in this multivariate model. Interestingly, the coefficients associated with the number of disorders did not change considerably with increasing number of disorders. From the 15 coefficients investigated (five groups of dummies for number of disorders by three partial disability subdomains; online Table DS4), only 5 were significant. This indicates additive interactions among disorders; that is, the joint effects of multiple disorders are additive to those of individual disorders.

\section{Society-level effects of physical and mental disorders on partial disability days}

Table 3 shows the PARP of days with partial disability caused by mental and physical disorders. The PARPs for physical disorders were considerably higher than those for mental disorders $(49.2 \%$ v. $14.7 \%)$. Back/neck pain $(\mathrm{PARP}=21.01 \%)$, arthritis $(\mathrm{PARP}=7.82 \%)$ and cardiovascular disease $(\mathrm{PARP}=7.22 \%)$ were the disorders that yielded the highest attributable risk (see also online Table DS5). When data were disaggregated for each of the three domains of partial disability, back/neck pain was among the disorders having the greatest impact on each of the three domains, with PARPs all in the $17-27 \%$ range (Table 3 ). A summary of PARP estimates is found in Fig. 1.

\section{Discussion}

Both physical and mental disorders are associated with considerable partial disability. Respondents with PTSD, generalised anxiety disorder, insomnia, bipolar disorder or panic disorder report up to 50 days per year with partial disability. On average, a person with any disorder reported about 19 additional partial disability days per year. This finding was more pronounced in high-income ( 23 additional days) than in middleand low-income countries (about 14 additional days). In particular, PTSD, depression and bipolar disorder yielded the greatest impact. By contrast, at the societal level, physical disorders yielded the highest PARPS; these accounted for $49 \%$ of the observed partial disability, compared with only $15 \%$ accounted for by mental disorders. 
Table 2 Additional partial disability days associated with mental and physical disorders: individual-level effects

\begin{tabular}{|c|c|c|c|c|c|c|c|c|}
\hline & \multicolumn{2}{|c|}{$\begin{array}{c}\text { Additional cut down } \\
\text { days }\end{array}$} & \multicolumn{2}{|c|}{$\begin{array}{l}\text { Additional cut back } \\
\text { days }\end{array}$} & \multicolumn{2}{|c|}{$\begin{array}{c}\text { Additional extreme } \\
\text { effort days }\end{array}$} & \multicolumn{2}{|c|}{$\begin{array}{c}\text { Any additional partial } \\
\text { disability }\end{array}$} \\
\hline & Mean (s.e.) & Rank & Mean (s.e.) & Rank & Mean (s.e.) & Rank & Mean (s.e.) & Rank \\
\hline \multicolumn{9}{|l|}{ Disorder } \\
\hline Depression & $1.30(0.16)$ & 5 & $1.28(0.15)$ & 2 & $1.57(0.16)$ & 2 & $1.65(0.18)$ & 3 \\
\hline Bipolar disorder & $1.47(0.35)$ & 2 & $1.28(0.34)$ & 3 & $1.14(0.36)$ & 6 & $1.70(0.45)$ & 2 \\
\hline Panic disorder & $1.06(0.27)$ & 8 & $0.98(0.22)$ & 8 & $1.22(0.23)$ & 5 & $1.28(0.24)$ & 7 \\
\hline Specific phobia & $0.41(0.14)$ & 17 & $0.61(0.16)$ & 13 & $0.74(0.17)$ & 13 & $0.70(0.16)$ & 15 \\
\hline Social phobia & $0.76(0.21)$ & 11 & $0.79(0.17)$ & 9 & $0.93(0.20)$ & 11 & $0.95(0.24)$ & 10 \\
\hline Generalised anxiety disorder & $1.37(0.32)$ & 3 & $0.99(0.33)$ & 7 & $0.98(0.29)$ & 9 & $1.35(0.39)$ & 6 \\
\hline Alcohol abuse & $0.36(0.18)$ & 18 & $0.32(0.16)$ & 18 & $0.23(0.17)$ & 19 & $0.41(0.19)$ & 18 \\
\hline Drug abuse & $0.43(0.35)$ & 16 & $0.67(0.36)$ & 12 & $0.84(0.39)$ & 12 & $0.77(0.50)$ & 13 \\
\hline Post-traumatic stress disorder & $1.60(0.30)$ & 1 & $1.62(0.30)$ & 1 & $1.66(0.30)$ & 1 & $1.92(0.42)$ & 1 \\
\hline Insomnia & $1.36(0.21)$ & 4 & $1.14(0.16)$ & 4 & $1.36(0.19)$ & 4 & $1.52(0.21)$ & 4 \\
\hline Headache or migraine & $0.53(0.11)$ & 15 & $0.52(0.10)$ & 17 & $0.57(0.11)$ & 16 & $0.67(0.19)$ & 17 \\
\hline Arthritis & $0.84(0.13)$ & 10 & $0.54(0.10)$ & 16 & $0.73(0.10)$ & 14 & $0.83(0.17)$ & 12 \\
\hline Back/neck pain & $1.25(0.11)$ & 6 & $1.12(0.09)$ & 5 & $1.38(0.10)$ & 3 & $1.49(0.28)$ & 5 \\
\hline Cardiovascular disease & $0.63(0.13)$ & 13 & $0.55(0.10)$ & 15 & $0.51(0.10)$ & 17 & $0.67(0.20)$ & 16 \\
\hline Respiratory disease & $0.25(0.10)$ & 19 & $0.26(0.08)$ & 19 & $0.26(0.09)$ & 18 & $0.31(0.13)$ & 19 \\
\hline Diabetes & $0.60(0.20)$ & 14 & $0.60(0.17)$ & 14 & $0.73(0.19)$ & 15 & $0.73(0.21)$ & 14 \\
\hline Digestive & $0.75(0.22)$ & 12 & $0.70(0.20)$ & 11 & $0.93(0.21)$ & 10 & $0.87(0.26)$ & 11 \\
\hline Neurological & $1.15(0.35)$ & 7 & $1.01(0.31)$ & 6 & $1.11(0.38)$ & 7 & $1.21(0.52)$ & 8 \\
\hline Cancer & $1.00(0.31)$ & 9 & $0.77(0.22)$ & 10 & $0.98(0.25)$ & 8 & $1.03(0.33)$ & 9 \\
\hline Any physical disorder & $1.26(0.07)$ & - & $1.05(0.04)$ & - & $1.24(0.05)$ & - & $1.42(0.25)$ & - \\
\hline Any mental disorder & $1.21(0.08)$ & - & $1.18(0.07)$ & - & $1.37(0.07)$ & - & $1.50(0.12)$ & - \\
\hline Any disorder & $1.38(0.07)$ & - & $1.16(0.04)$ & - & $1.37(0.05)$ & - & $1.58(0.24)$ & - \\
\hline
\end{tabular}

\section{Limitations}

These results should be interpreted in the light of the following limitations. First, only a restricted set of common mental and physical disorders was included in the analyses; some of these were pooled to form larger disorder groups. A number of burdensome disorders, such as dementia and psychosis, were not included. Nonetheless, the disorders we did consider included many of those most commonly reported in previous population studies. ${ }^{8}$ Further study should focus on possibly high-impact disorders that were not included in the present study. A second limitation pertains to the self-report method we used to assess physical disorders. Since the WMH Surveys were conducted in many population samples, it was not feasible to include a more comprehensive assessment of physical disorders. Although prior research has demonstrated reasonable correspondence between self-reported chronic disorders (such as diabetes, heart disease and asthma) and general practitioner records, ${ }^{29}$ previous studies have suggested that self-report measures may be more amenable to underreporting bias than behavioural measures or physical examinations. Indeed, these may be biased by cultural norms ${ }^{30,31}$ or demographic factors (such as lower education or poor health literacy). There is even some evidence that that self-reported somatic disorders tend to be forgotten. ${ }^{32,33}$ This suggests that we may have underestimated the contribution of somatic disorders to partial disability. Third, the time frame in which we assessed partial disability was limited to the 30 days prior to the interview, in order to increase the validity of self-reports. Despite this, for more episodic disorders, the recall period might have missed a severe exacerbation present in the previous year, but not in the month before the interview.

\section{Main findings}

Notwithstanding these limitations, several findings from the present study extend the existing literature. For a given respondent, mental disorders (mostly depression, bipolar disorder and PTSD) are associated with a significant additional increase in partial disability days, even after rigorously controlling for a broad set of sociodemographic variables and comorbidity. These findings extend earlier work ${ }^{8,13,34-36}$ by showing that mental disorders are associated with partial disability, over and above full disability. To the best of our knowledge, our study is the first cross-national study comparing the relative impact of disorders in respondents who indicate that they are not fully out of role in their daily functioning. Some of the results we found differed from those in previous studies. ${ }^{9}$ This could be the result of some methodological differences between this and previous studies. For example, previous studies often did not adjust disability for comorbidity patterns of disorders. We also extend previous findings by investigating decrements in day-to-day functioning that go beyond mere job productivity ${ }^{4}$ and instead focus on a broader understanding of functioning.

The set of physical and mental disorders included in this study accounted for more than half of all partial disability days. If we look at individual mental disorders, depression in particular is of interest given its relatively high 12 -month prevalence $(>5 \%)$, its considerable effect on partial disability (about 20 additional days per year), as well as its relatively high population attributable risk (about 6\%). By contrast, among physical disorders, back/neck pain is of interest because it is a highly prevalent condition (with estimates around 22\%) yielding 18 additional disability days per year. Moreover, approximately a fifth of all partial disability was attributable to this condition. The same pattern applies to arthritis, but to a lesser extent. It is interesting that previous studies, although they often used different methodological approaches, also ranked back/neck pain and depression as being among the disorders having the greatest impact both at the individual and societal level. ${ }^{7,37,38}$ From a public health perspective, depression and back/neck pain may be a focus for prioritisation when deciding upon resource allocation.

For a given respondent, the type of partial disability caused by disorders is quite similar: mental disorders cause about 14-16 additional days with partial disability per year. Comparable figures for physical disorders were 13-15 additional disability days. We could not confirm that mental disorders (compared with physical 


\begin{tabular}{|c|c|c|c|c|c|c|c|c|}
\hline & \multicolumn{2}{|c|}{$\begin{array}{l}\text { Additional cut down } \\
\text { days }\end{array}$} & \multicolumn{2}{|c|}{$\begin{array}{l}\text { Additional cut back } \\
\text { days }\end{array}$} & \multicolumn{2}{|c|}{$\begin{array}{c}\text { Additional extreme } \\
\text { effort days }\end{array}$} & \multicolumn{2}{|c|}{$\begin{array}{c}\text { Any additional partial } \\
\text { disability }\end{array}$} \\
\hline & Mean (s.e.) & Rank & Mean (s.e.) & Rank & Mean (s.e.) & Rank & Mean (s.e.) & Rank \\
\hline \multicolumn{9}{|l|}{ Disorder } \\
\hline Depression & $4.49(0.55)$ & 5 & $6.90(0.84)$ & 5 & $7.60(0.77)$ & 3 & $5.86(1.23)$ & 5 \\
\hline Bipolar disorder & $0.69(0.17)$ & 17 & $0.93(0.25)$ & 17 & $0.75(0.24)$ & 17 & $0.82(0.35)$ & 17 \\
\hline Panic disorder & $1.22(0.31)$ & 13 & $1.76(0.40)$ & 13 & $1.97(0.38)$ & 12 & $1.51(0.48)$ & 12 \\
\hline Specific phobia & $1.33(0.46)$ & 12 & $3.09(0.81)$ & 8 & $3.35(0.78)$ & 8 & $2.32(0.67)$ & 8 \\
\hline Social phobia & $1.14(0.32)$ & 14 & $1.83(0.41)$ & 12 & $1.95(0.41)$ & 13 & $1.46(0.62)$ & 13 \\
\hline Generalised anxiety disorder & $1.14(0.27)$ & 15 & $1.28(0.43)$ & 15 & $1.15(0.35)$ & 15 & $1.15(0.51)$ & 15 \\
\hline Alcohol abuse & $0.47(0.23)$ & 18 & $0.66(0.33)$ & 18 & $0.43(0.32)$ & 19 & $0.55(0.32)$ & 18 \\
\hline Drug abuse & $0.16(0.13)$ & 19 & $0.38(0.20)$ & 19 & $0.43(0.20)$ & 18 & $0.29(0.23)$ & 19 \\
\hline Post-traumatic stress disorder & $1.42(0.28)$ & 10 & $2.23(0.44)$ & 10 & $2.06(0.40)$ & 11 & $1.75(0.70)$ & 11 \\
\hline Insomnia & $4.08(0.64)$ & 6 & $5.30(0.76)$ & 6 & $5.72(0.81)$ & 6 & $4.69(0.91)$ & 6 \\
\hline Headache or migraine & $4.61(0.99)$ & 4 & $7.06(1.35)$ & 4 & $6.94(1.31)$ & 5 & $5.99(1.03)$ & 4 \\
\hline Arthritis & $7.70(1.23)$ & 2 & $7.65(1.45)$ & 3 & $9.43(1.29)$ & 2 & $7.82(1.31)$ & 2 \\
\hline Back/neck pain & $17.17(1.55)$ & 1 & $24.03(1.95)$ & 1 & $26.65(1.85)$ & 1 & $21.01(2.43)$ & 1 \\
\hline Cardiovascular disease & $6.56(1.35)$ & 3 & $8.99(1.64)$ & 2 & $7.50(1.51)$ & 4 & $7.22(1.30)$ & 3 \\
\hline Respiratory disease & $2.75(1.06)$ & 7 & $4.38(1.45)$ & 7 & $4.02(1.36)$ & 7 & $3.53(1.13)$ & 7 \\
\hline Diabetes & $1.50(0.51)$ & 9 & $2.37(0.66)$ & 9 & $2.58(0.66)$ & 10 & $1.90(0.83)$ & 9 \\
\hline Digestive & $1.52(0.44)$ & 8 & $2.20(0.65)$ & 11 & $2.65(0.60)$ & 9 & $1.83(0.84)$ & 10 \\
\hline Neurological & $0.78(0.24)$ & 16 & $1.07(0.33)$ & 16 & $1.06(0.36)$ & 16 & $0.85(0.51)$ & 16 \\
\hline Cancer & $1.35(0.42)$ & 11 & $1.61(0.46)$ & 14 & $1.85(0.48)$ & 14 & $1.43(0.69)$ & 14 \\
\hline Any physical disorder & $42.23(2.20)$ & - & $54.89(2.28)$ & - & $58.47(1.96)$ & - & $49.15(4.88)$ & - \\
\hline Any mental disorder & $11.53(0.80)$ & - & $17.47(1.13)$ & - & $18.29(0.96)$ & - & $14.73(3.96)$ & - \\
\hline Any disorder & $50.51(2.55)$ & - & $66.11(2.51)$ & - & $70.01(2.29)$ & - & $59.42(6.75)$ & - \\
\hline
\end{tabular}

disorders) were more likely associated with an increase in both the number of partial and total disability days, as suggested in previous research. Indeed, Dewa and colleagues ${ }^{5}$ found that mental disorders yielded 23 times more total disability days than partial disability days. If we compare the impact of mental/ physical disorders on both the number of days where respondents were totally out of role ${ }^{13}$ or partially out of role (this study), it is striking that the impact of mental disorders is quite similar to that of physical disorders. In line with this, it was also suggested that mental and physical disorders were similar in their impact on costs of illness. ${ }^{39}$
The impact of disorders on partial disability was most pronounced in high-income countries. In low-income countries, estimates of both individual and societal effects of mental disorders on partial disability were systematically $33-50 \%$ lower than those of middle- or high-income countries. This was also the case for physical disorders, although to a lesser extent (i.e. about $15-46 \%$ ). The impact of disorders on partial disability was consistently lower in low-income countries, in contrast to the effect disorders have on days totally out of role. ${ }^{13}$ As this is the first study that investigated cross-income effects, further research should point us to whether these effects can be confirmed.

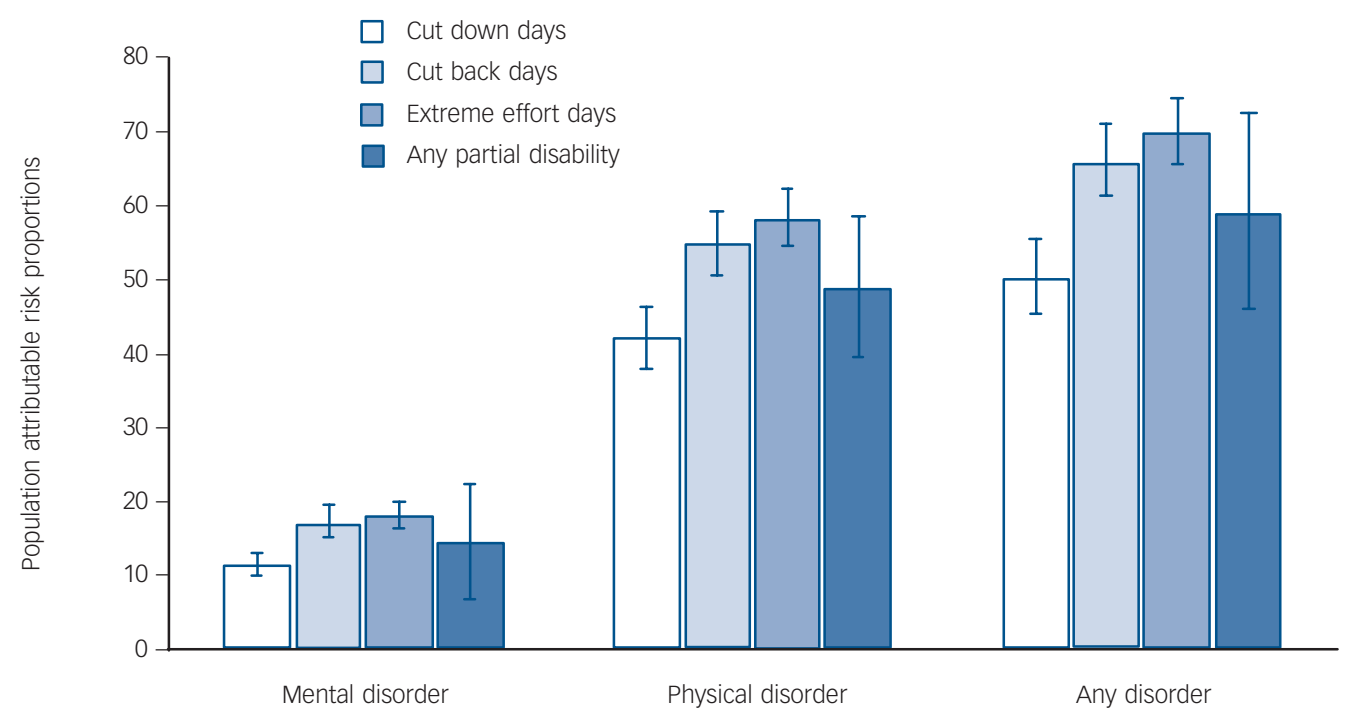

Fig. 1 Estimated proportion of partial disability attributable to common mental and physical disorders in the World Mental Health Surveys (population attributable risk proportions). 


\section{Implications}

The results obtained in this study may have some important implications. Given that mental and physical disorders yield a similar impact on partial disability, this sheds light on the importance of prioritising public health needs. To the extent that partial disability may be a predictor of full disability, ${ }^{12}$ our data underscore the importance of including partial disability when evaluating functional impairment. Our data indicate that a reduction in depression and back/neck pain could be considered as a public health priority, especially given the knowledge that these disorders (a) have a high impact at both an individual and societal level; (b) cause both full disability and partial disability days; and (c) have a considerable comorbidity in both clinical and general population settings. ${ }^{40}$ How this may be done at country level remains an open question. Prevention, integrated treatment and supportive services have been suggested, ${ }^{41}$ but the alleviation of this substantial burden of ill health, in both personal and economic terms, remains a significant challenge.

Ronny Bruffaerts, PhD, Universitair Psychiatrisch Centrum - Katholieke Universiteit Leuven (UPC-KUL), University Hospital Gasthuisberg, Leuven, Belgium; Gemma Vilagut, MS, Health Services Research Unit, Institut Municipal d'IInvestigació Mèdica (IMIM-Hospital del Mar) and CIBER en Epidemiología y Salud Pública (CIBERESP), Barcelona, Spain; Koen Demyttenaere, MD, PhD, Universitair Psychiatrisch Centrum - Katholieke Universiteit Leuven (UPC-KUL), University Hospital Gasthuisberg, Leuven, Belgium; Jordi Alonso, MD, PhD, Health Services Research Unit, Institut Municipal d'Investigació Mèdica (IMIM-Hospital del Mar) and CIBER en Epidemiología y Salud Pública (CIBERESP), Barcelona, Spain; Ali AlHamzawi, MBChB, MD, FICMS, Iraq, Diwania governorate, Al-Qadisia University, College of Medicine, Iraq; Laura Helena Andrade, MD, PhD, Section of Psychiatric Epidemiology - LIM 23 Department and Institute of Psychiatry School of Medicine, University of São Paulo, São Paulo, Brazil; Corina Benjet, PhD, National Institute of Psychiatry, Mexico City, Mexico; Evelyn Bromet, PhD, State University of New York (SUNY) at Stonybrook, New York, USA; Brendan Bunting, PhD, School of Psychology, University of Ulster, Belfast, Northern Ireland; Giovanni de Girolamo, PhD, IRCCS Centro S. Giovanni di Dio Fatebenefratelli, Brescia, Italy; Silvia Florescu, MD, PhD, Scoala Nationala de Sanatate Publica si Perfectionare in Domeniul Sanitar, Bucuresti, Romania; Oye Gureje, MB, PhD, DSC, University College Hospital, Ibadan, Nigeria; Josep Maria Haro, MD, MPH, PhD, Parc Sanitari Sant Joan de Déu, CIBERSAM, Sant Boi de Llobregat, Barcelona, Spain; Yanling He, MD, Shanghai Mental Health Center, Shanghai, People's Republic of China; Hristo Hinkov, MD, Department of Global Mental Health, National Center for Public Health Protection, Sofia, Bulgaria; Chiyi Hu $\mathrm{MD}, \mathrm{PhD}$, Shenzhen Institute of Mental Health \& Shenzhen Kangning Hospital, Shenzhen, People's Republic of China; Elie G. Karam, MD, St George Hospital University Medical Center, Balamand University, Faculty of Medicine, Institute for Development, Research, Advocacy \& Applied Care (IDRAAC), Medical Institute for Neuropsychological Disorders (MIND), Beirut, Lebanon; Jean-Pierre Lepine, MD, HDR, Hôpital Lariboisière Fernand Widal, Assistance Publique Hôpitaux de Paris INSERM U705, University Paris Diderot and Paris Descartes Paris, France; Daphna Levinson, MA, PhD, Research \& Planning, Mental Health Services Ministry of Health Jerusalem, Israel; Herbert Matschinger, PhD, Institut of Social Medicine, Occupational Health and Public Health University of Leipzig, Germany; Yoshibumi Nakane, MD, Division of Human Sociology, Nagasaki International University Graduate School Nagasaki, Japan; Johan Ormel, MA, PhD, Interdisciplinary Center for Psychiatric Epidemiology, Department of Psychiatry, University Medical Center Groningen, University of Groningen, The Netherlands; Jose Posada-Villa, MD, MS, Instituto Colombiano del Sistema Nervioso, Bogota, Colombia; Kate M. Scott, PhD, Department of Psychological Medicine, Wellington School of Medicine and Health Sciences, Wellington, New Zealand; Matthew Varghese, PhD, Adult, Geriatric \& Family Psychiatry Units, National Institute of Mental Health \& Neuro Sciences (NIMHANS), Delhi, India; David R. Williams, MPH, PhD, Department of Public Health Department of Society, Human Development, and Health, Harvard School of Public Health, Boston, USA; Miguel Xavier, MD, PhD, Department of Mental Health CEDOC, Faculdade Ciencias Medicas - UNL, Lisbon, Portugal; Ronald C. Kessler PhD, Department of Health Care Policy, Harvard Medical School, Boston, USA

Correspondence: Ronny Bruffaerts, Universitair Psychiatrisch Centrum Katholieke Universiteit Leuven (UPC-KUL), campus Leuven, Herestraat 49, B-3000 Leuven, Belgium. Email: ronny.bruffaerts@med.kuleuven.be

First received 3 Jun 2011, final revision 2 Nov 2011, accepted 17 Jan 2012

\section{Funding}

The World Health Organization (WHO) World Mental Health (WMH) Survey Initiative is supported by the US National Institute of Mental Health (NIMH; R01MH070884), the Mental Health Burden Study: Contract number HHSN271200700030C, the John D. and Catherine T. MacArthur Foundation, the Pfizer Foundation, the US Public Health Service (R13MH066849, R01-MH069864, and R01 DA016558), the Fogarty International Center (FIRCA R03-TW006481), the Pan American Health Organization (PAHO), the Eli Lilly \& Company Foundation, Ortho-McNeil Pharmaceutical, GlaxoSmithKline, Bristol-Myers Squibb and Shire. The São Paulo Megacity Mental Health Survey is supported by the State of São Paulo
Research Foundation (FAPESP) Thematic Project Grant 03/00204-3. The Bulgarian Epidemiological Study of common mental disorders EPIBUL is supported by the Ministry of Health and the National Center for Public Health Protection. The Chinese World Mental Health Survey Initiative is supported by the Pfizer Foundation. The Shenzhen Mental Health Survey is supported by the Shenzhen Bureau of Health and the Shenzhen Bureau of Science, Technology, and Information. The Colombian National Study of Mental Health (NSMH) is supported by the Ministry of Social Protection. The ESEMED project is funded by the European Commission (ContractS QLG5-1999-01042; SANCO 2004123), the Piedmont Region (Italy), Fondo de Investigación Sanitaria, Instituto de Salud Carlos III, Spain (FIS 00/ 0028), Ministerio de Ciencia y Tecnología, Spain (SAF 2000-158-CE), Departament de Salut, Generalitat de Catalunya, Spain, Instituto de Salud Carlos III (CIBER CB06/02/0046, RETICS RD06/0011 REM-TAP), and other local agencies and by an unrestricted educational grant from GlaxoSmithKline. The Epidemiological Study on Mental Disorders in India was funded jointly by Government of India and WHO. Implementation of the Iraq Mental Health Survey (IMHS) and data entry were carried out by the staff of the Iraqi MOH and MOP with direct support from the Iraqi IMHS team with funding from both the Japanese and European Funds through United Nations Development Group Iraq Trust Fund (UNDG ITF). The Israel National Health Survey is funded by the Ministry of Health with support from the Israel National Institute for Health Policy and Health Services Research and the National Insurance Institute of Israel. The World Mental Health Japan (WMHJ) Survey is supported by the Grant for Research on Psychiatric and Neurological Diseases and Mental Health (H13-SHOGAI-023, H14-TOKUBETSU-026, H16-KOKORO-013) from the Japan Ministry of Health, Labour and Welfare. The Lebanese National Mental Health Survey (LEBANON) is supported by the Lebanese Ministry of Public Health, the WHO (Lebanon), Fogarty International, anonymous private donations to IDRAAC, Lebanon, and unrestricted grants from Janssen-Cilag, Eli Lilly, GlaxoSmithKline, Roche and Novartis. The Mexican National Comorbidity Survey (MNCS) is supported by the National Institute of Psychiatry Ramon de la Fuente (INPRFMDIES 4280) and by the National Council on Science and Technology (CONACYT-G30544- H), with supplemental support from PAHO. Te Rau Hinengaro: The New Zealand Mental Health Survey (NZMHS) is supported by the New Zealand Ministry of Health, Alcohol Advisory Council, and the Health Research Council. The Nigerian Survey of Mental Health and Wellbeing (NSMHW) is supported by the WHO (Geneva), the WHO (Nigeria), and the Federal Ministry of Health, Abuja, Nigeria. The Northern Ireland Study of Mental Health was funded by the Health \& Social Care Research \& Development Division of the Public Health Agency. The Portuguese Mental Health Study was carried out by the Department of Mental Health, Faculty of Medical Sciences, NOVA University of Lisbon, with collaboration of the Portuguese Catholic University, and was funded by Champalimaud Foundation, Gulbenkian Foundation, Foundation for Science and Technology (FCT) and Ministry of Health. The Romania WMH study projects 'Policies in Mental Health Area' and 'National Study regarding Mental Health and Services Use' were carried out by National School of Public Health \& Health Services Management (former National Institute for Research \& Development in Health), with technical support of Metro Media Transilvania, the National Institute of Statistics-National Centre for Training in Statistics, SC. Cheyenne Services SRL, Statistics Netherlands and were funded by Ministry of Public Health (former Ministry of Health) with supplemental support of Eli Lilly Romania SRL. The South Africa Stress and Health Study (SASH) is supported by the US NIMH (R01-MH059575) and National Institute of Drug Abuse (NIDA) with supplemental funding from the South African Department of Health and the University of Michigan. The Ukraine Comorbid Mental Disorders during Periods of Social Disruption (CMDPSD) study is funded by the US NIMH (R01-MH61905). The US National Comorbidity Survey Replication (NCS-R) is supported by the NIMH (U01-MH60220) with supplemental support from NIDA, the Substance Abuse and Mental Health Services Administration (SAMHSA), the Robert Wood Johnson Foundation (RWJF; Grant 044708) and the John W. Alden Trust.

\section{Acknowledgements}

This report is carried out in conjunction with the World Health Organization World Mental Health (WMH) Survey Initiative. We thank the WMH staff for assistance with instrumentation, fieldwork and data analysis. A complete list of WMH publications can be found at http://www.hcp.med.harvard.edu/wmh/.

\section{References}

1 Goetzel RZ, Long SR, Ozminkowski RJ, Hawkins K, Wang S, Lynch W. Health, absence, disability, and presenteeism cost estimates of certain physical and mental health conditions affecting US employers. J Occup Environ Med 2004; 46: 398-412.

2 Lerner D, Allaire SH, Reisine ST. Work disability resulting from chronic health conditions. J Occup Environ Med 2005; 47: 253-64.

3 Kessler RC, Frank RG. The impact of psychiatric disorders on work loss days. Psychol Med 1997; 27: 861-73.

4 Dewa C, Lin E. chronic physical illness, psychiatric disorder and disability in the workplace. Soc Sci Med 2000; 51: 41-50.

5 Dewa CS, Lesage A, Goering P, Caveen M. Nature and prevalence of mental illness in the workplace. Healthc Pap 2004; 5: 12-25.

6 Ormel J, Von Korff M, Üstün TB, Pini S, Korten A, Oldehinkel T. Common mental disorders and disability across cultures: results from the WHO Collaborative Study on Psychological Problems in General Health Care. JAMA 1994; 272: 1741-8.

7 Merikangas KR, Ames M, Cui L, Stang PE, Ustun TB, Von Korff M, et al. The impact of comorbidity of mental and physical disorders on role disability in the US adult household population. Arch Gen Psychiatry 2007; 64: 1180-8.

8 Alonso J, Angermeyer M, Bernert S, Bruffaerts R, Brugha TS, Bryson H, et al. Disability and quality of life impact of mental disorders in Europe : results 
from the European Study on Epidemiology of Mental Disorders (ESEMeD) project. Acta Psychiatr Scand 2004; 109 (suppl 420): 38-46.

9 Heffler S, Smith S, Won G, Clemens MK, Keehan S, Zezza M. Health spending projections for 2001-2011: the latest outlook. Health Aff (Millwood) 2002; 21: 207-18.

10 World Health Organization. World Report on Disability. WHO Press, 2011.

11 Bergström G, Bodin L, Hagberg J, Aronsson G, Josephson M. Sickness presenteeism today, sickness absenteeism tomorrow? A prospective study on sickness presenteeism and future sickness absenteeism. J Occup Environ Med 2009; 51: 629-38

12 Dewa CS, Lin E, Koehoorn M, Goldner E. Association of chronic work stress, psychiatric disorders, and chronic physical conditions with disability among workers. Psychiatr Serv 2007; 58: 652-8.

13 Alonso J, Petukova M, Vilagut G, Chatterji S, Heeringa S, Üstün TB, et al. Days out of role due to common physical and mental conditions: results from the WHO World Mental Health Surveys. Mol Psychiatr 2010; 16: 1234-46.

14 World Bank. Data and Statistics. World Bank, 2008 (http://data-worldbank. org/about/country-classifications).

15 Heeringa SG, Wells JE, Frost H, Mneimneh ZN, Chiu GT, Sampson NA, et al. Sample designs and sampling procedures. In The WHO World Mental Health Surveys: Global Perspectives on the Epidemiology of Mental Disorders (eds RC Kessler and T Bedirhan Üstün): 14-32. Cambridge University Press, 2008.

16 Pennell BE, Mneimneh ZN, Bowers A, Chardoul S, Wells JE, Viana MC, et al Implementation of the World Mental Health Surveys. In The WHO World Mental Health Surveys: Global Perspectives on the Epidemiology of Mental Disorders (eds RC Kessler, TB Üstün): 33-57. Cambridge University Press, 2008.

17 Harkness J, Pennell BE, Villar A, Gebler N, Aguilar-Gaxiola S, Bilgen I. Translation procedures and translation assessment in the World Mental Health Survey initiative. In The WHO World Mental Health Surveys: Global Perspectives on the Epidemiology of Mental Disorders (eds RC Kessler, TB Üstün): 91-113. Cambridge University Press, 2008.

18 Von Korff M, Crane PK, Alonso J, Vilagut G, Angermeyer MC, Bruffaerts R, et al. Modified WHODAS-II provides valid measure of global disability but filter items increased skewness. J Clin Epidemiol 2008; 61: 1132-43.

19 Kessler RC, Ames M, Hymel PA, Loeppke R, McKenas DK, Richling DE, et al. Using the World Health Organization Health and Work Performance Questionnaire (HPQ) to evaluate the indirect workplace costs of illness. J Occup Environ Med 2004; 46: S23-37.

20 National Center for Health Statistics. Evaluation of National Health Interview Survey diagnostic reporting. Vital Health Stat 1994; 120: 1-116.

21 Center for Disease Control and Prevention. Health, United States, 2004. US Government Printing Office, 2004.

22 Schoenborn CA, Adams PF, Schiller JS. Summary health statistics for the U.S population: National Health Interview Survey, 2000. Vital Health Stat 2003; 10: $1-83$.

23 Knight M, Stewart-Brown S, Fletcher L. Estimating health needs: the impact of a checklist of conditions and quality of life measurement on health information derived from community surveys. J Public Health Med 2001; 23: 179-86.
24 Baker MM, Stabile M, Deri C. What Do Self-reported, Objective Measures of Health Measure? National Bureau of Economic Research, 2001.

25 Kessler RC, Ustun TB. The World Mental Health (WMH) Survey Initiative version of the World Health Organization (WHO) Composite International Diagnostic Interview (CIDI). Int J Methods Psychiatr Res 2004; 13: 93-121.

26 Wittchen HU. Reliability and validity studies of the WHO Composite International Diagnostic Interview (CIDI): a critical review. J Psychiatr Res 1994; 28: 57-84.

27 Haro JM, Arbabzadeh-Bouchez S, Brugha TS, de Girolamo G, Guyer ME, Jin R, et al. Concordance of the Composite International Diagnostic Interview Version 3.0 (CIDI 3.0) with standardized clinical assessments in the WHO World Mental Health surveys. Int J Methods Psychiatr Res 2006; 15: 167-80.

28 Wolter KM. Introduction to Variance Estimation. Springer-Verlag, 1985.

29 Kriegsman DM, Penninx BW, van Eijk JT, Boeke AJ, Deeg DJ. Self-reports and general practitioner information on the presence of chronic diseases in community dwelling elderly. A study on the accuracy of patients' selfreports and on determinants of inaccuracy. J Clin Epidemiol 1996; 49: 1407-17.

30 Solomon P. Congruence between health professionals' and patients' pain ratings: a review of the literature. Scand J Caring Sci 2001; 15: 174-80.

31 Harrison A. Assessing patients' pain: identifying reasons for error. J Adv Nurs 1991; 16: 1018-25.

32 Jamison RN, Raymond SA, Slawsby EA, McHugo GJ, Baird JC. Pain assessment in patients with low back pain: comparison of weekly recall and momentary electronic data. J Pain 2006; 7: 192-9.

33 Biering-Sorensen F, Hilden J. Reproductivity of the history of low back trouble. Spine 1984; 9: 280-6.

34 Polder JJ, Achterberg PW. Cost of IIIness in the Netherlands. National Institute for Public Health and the Environment, 2004.

35 Buist-Bouwman MA, de Graaf R, Vollebergh WA, Ormel J. Comorbidity of physical and mental disorders and the effect on work-loss days. Acta Psychiatr Scand 2005; 111: 436-43.

36 Kessler RC, Ormel J, Demler O, Stang PE. Comorbid mental disorders account for the role impairment of commonly occurring chronic physical conditions: results from the National Comorbidity Survey. J Occup Environ Med 2003; 45: 1257-66.

37 Knight M, Stewart-Brown S, Fletcher L. Estimating health needs: the impact of a checklist of conditions and quality of life measurement on health information derived from communirt surveys. J Public Health Med 2001; 23: 179-86.

38 Stewart WF, Ricci JA, Chee E, Morganstein D, Lipton R. Lost productive time and cost due to common pain conditions in the US workforce. JAMA 2003; 290: $2443-54$

39 Smit F, Cuijpers P, Oostenbrink J, Batelaan N, de Graaf R, Beekman A. Costs of nine common mental disorders: implications for curative and preventive psychiatry. J Ment Health Policy Econ 2006; 9: 193-200.

40 Bair MJ, Robinson RL, Katon W, Kroenke K. Depression and pain comorbidity. Arch Intern Med 2003; 163: 2433-45.

41 Katschnig H, Freeman H, Sartorius N. Quality of Life in Mental Disorders. Wiley, 1997. 